\title{
Response to Akar et al., regarding our study "Side effects to continuous positive airway pressure treatment for obstructive sleep apnoea"
}

\author{
Martin Ulander ${ }^{1,2} \cdot$ Anders Broström ${ }^{1,3}$
}

Received: 10 February 2015 /Revised: 18 March 2015 / Accepted: 25 March 2015 / Published online: 19 April 2015

(C) Springer-Verlag Berlin Heidelberg 2015

We would like to thank Akar et al. for their interest in our study [1], and for their comments on it.

Side effect data were collected using SECI (Side Effects to Continuous Positive Airway Pressure (CPAP) Inventory), which is a self-report instrument for CPAP side effects that was developed by our group for a previous study [2]. That is, eye irritation as well as other side effects were reported by the patients, and were not based on an ophthalmological examination. We did not use the Ocular Surface Disease Index as our study did not focus specifically on eye-related side effects. In the interest of reducing the number of items (SECI itself in the version used in the study contains 45 items), it was deemed inappropriate to include specific questionnaires for each particular side effect. We agree that it would be valuable to assess the correlation between item 5 in SECI (i.e. irritated eyes) and the results of an ophthalmological examination, but that was not part of the aim of the study in question. Our main interest in self-reported CPAP side effects stems from the fact that they may affect treatment adherence, which is documented to be suboptimal in many studies [3]. Although there may be an association between objective findings and subjective reports

Martin Ulander

Martin.Ulander@liu.se

1 Department of Clinical Neurophysiology, Linköping University Hospital, Linköping S-581 85, Sweden

2 Department of Clinical Neurophysiology, Institution for Clinical and Experimental Medicine, Faculty of Health Sciences, Linköping University, Linköping S-581 83, Sweden

3 Department of Nursing, School of Health Sciences, Jönköping University, Jönköping, Sweden with regard to those side effects that can be assessed objectively (e.g. eye irritation, but not, for example anxiety), selfreported CPAP side effects are more complex, as other factors (e.g. personality, see ref. 2) may affect the perceived prevalence and severity of side effects. If side effects are of importance for adherence, it is more likely that a patient's perception of irritated eyes, for example, is associated with adherence rather than the tear film break-up time, although objective ophthalmological findings are likely to be related to perceived subjective symptoms. What medical, psychological and treatment-related factors that may lead to certain side effects is of course an important and interesting research question in its own right, but not what our study aimed at investigating. In conclusion, we do not think that our findings contradict the findings reported by you, especially as our aims, and therefore, our study design differ from yours.

Conflicts of interest None of the authors have any conflicts of interest to disclose.

\section{References}

1. Ulander M, Johansson MS, Ewaldh AE, Svanborg E, Broström A (2014) Side effects to continuous positive airway pressure treatment for obstructive sleep apnoea: changes over time and association to adherence. Sleep Breath 18:799-807

2. Broström A, Strömberg A, Mårtensson J, Ulander M, Harder L, Svanborg E (2007) Association of Type D personality to perceived side effects and adherence in CPAP-treated patients with OSAS. J Sleep Res 16:439-447

3. Wozniak DR, Lasserson TJ, Smith I (2014) Educational, supportive and behavioural interventions to improve usage of continuous positive airway pressure machines in adults with obstructive sleep apnoea. Cochrane Database of Systematic Reviews 2014, Issue 1. Art. No.: CD007736 